Bensing, J., Dulmen, S. van, Tates, $\mathrm{K}$.

Communication in context: new directions in communication research.

Patient Education and Counseling: 50, 2003, nr. 1, p. 27-32

\begin{tabular}{|l|l|}
\hline $\begin{array}{l}\text { Postprint version } \\
\text { Journal website }\end{array}$ & $\begin{array}{l}1.0 \\
\text { http://www.sciencedirect.com }\end{array}$ \\
\hline $\begin{array}{l}\text { Pubmed link } \\
\text { http://www.ncbi.nlm.nih.gov/entrez/query.fcgi?db=pubmed\&cmd=Retrieve\&do } \\
\text { pt=Abstract\&list uids=12767581\&query hl=35\&itool=pubmed docsum }\end{array}$ \\
\hline DOI & \begin{tabular}{l}
$10.1016 /$ S0738-3991(03)00076-4 \\
\hline
\end{tabular}
\end{tabular}

*Corresponding author. Tel.: +31-30-27-29-700; fax: +31-30-27-29-729.

E-mail address: j.bensing@nivel.nl (J. Bensing).

\title{
Communication in context: new directions in communication research
}

\author{
JOZIEN BENSING*, SANDRA VAN DULMEN, KIEK TATES \\ NIVEL, P.O. Box 1568, 3500 BN Utrecht, The Netherlands
}

\begin{abstract}
By focusing attention almost exclusively on a single encounter, researchers have adopted a rather restricted view on studying communication in health care. After all, communication does not take place in a vacuum but is influenced by the context in which it takes place. We would therefore strongly recommend to broaden the perspective of communication research. In this respect, four lines of investigation are proposed, each guided by different theories. In the first, context is determined by the goals or targets aimed at by both parties in the medical encounter. The second concerns the context of time, referring to the influence of previous and future medical encounters. The third is set up around the organizational context in which an interaction takes place and the last defines context by looking at a medical encounter as a meeting between two multifaceted parties. Studying a medical encounter in its broader context is expected to provide answers to intriguing questions such as why health care professionals do not always act in conformity with the general approved standards of high quality communication and how the factor time span can be used more effectively in the medical encounter. Eventually, a broader context view will bridge the existing gap between theory and practice.
\end{abstract}

\section{INTRODUCTION}

Research into medical communication is sometimes described as analyzing the black box of the doctor's healing power $[1,2]$. However, every now and then a picture emerges of communication researchers analyzing this black box as if it was found in the bush after a plane crash: as an object in itself, completely devoid of the wider context of the medical dialogue. Most communication research has been exclusively focused on the dialogue between patient and doctor or nurse in itself, without taking account of its broader context. But no dialogue takes place in a vacuum; there is a whole world surrounding it. We strongly believe that this narrow focus blinds communication researchers to many relevant issues, and hampers the progress of knowledge as well as its implementation in clinical practice.

Our central statement in this position paper is: We have acquired enough knowledge in general of the value of communication skills. Now, it is time to focus our attention to the study of specific contextual conditions that may broaden our knowledge and may help, hinder or complicate the application of this knowledge in everyday practice. The community of researchers should feel challenged to look for new 
roads in order to substantiate the so often claimed central position of communication in clinical practice, medical education, and in research programs.

\section{FUTURE CHALLENGES}

A running thread in our position paper is the call for attention to the context of medical communication. In general, there is much agreement-among teachers as well as researchers—on the basics of good communication in health care. There is ample evidence that communication should be considered as a powerful tool in medicine, not only in establishing a workable relationship with the patient, but also in both the diagnostic and therapeutic process [1-6]. It has also been shown to work the other way around: Good technical quality care, provided in an unsatisfactory environment and with unsatisfactory interactions will not produce healthier patients [7], and negative expectancies increase the frequency with which patients report all kind of symptoms [4]. Consciously or unconsciously, communication plays a crucial role in medical practice. However, in order to understand the real contribution of communication to distinctive outcomes of health care, we are convinced that communication has to be studied in its broader context, the context of aims and targets, the context of persons and organizations, the context of place and time. By doing so, we hope to bridge the gap between evidence-based medicine and patient-centered medicine [2] and to find empirical evidence for the mechanisms which foster or hinder patients' well-being, apart from the direct effects of the medical intervention itself: those mechanisms that are known to be part of the much-discussed, but little-researched placebo and nocebo-effects in health care [8].

There is, however, yet another challenge to meet: the challenge of theory-driven research. Much communication research is still descriptive in nature, more dictated by available methodology than by rigorous application of dedicated theories. Descriptive research is useful in the earlier stages of knowledge-production, when the domain-under-study still has to be charted. Real breakthroughs in knowledge are, however, only possible by systematically testing theory-guided hypotheses on presumed mechanisms behind the (positive and negative) effects of communication. We believe that in health care the phase of exploratory and descriptive research should and could be over.

\section{TOWARDS A NEW RESEARCH AGENDA}

Taken together, these two challenges can help us to define a research agenda for the next decade.

Within the field of communication in context, four lines of investigation should be distinguished:

1. The context of goals or targets of both parties in the medical encounter (patient and physician or nurse), referring to 'the use of communication as a tool'.

2. The context of time in relation to continuity of care which necessitates to investigate not only one single visit but to consider the role and influence of previous and future consultations and patient's medical history as well.

3. The broader organizational context in which the dialogue takes place, colored by policies regarding teamwork, time constraints and implicit and explicit priorities within the medical staff.

4. The context determined by what both multifaceted parties — on the one hand the patient and accompanying wife, husband or child, on the other the physician, nurse, and/or other care providers-bring to the health care visit: needs, expectations and knowledge and attitudes, experience and skills, respectively.

In presenting these four lines of investigation, we do not claim to provide an exhaustive overview of potential studies in the area of context in health care. Our purpose is merely to touch on the, until now, underexposed fields of study. Each of the lines of investigation will be elaborated and put in the proper theoretical perspective.

\subsection{From general to specific}

In line with the tradition in communication research, we started by emphasizing the central role of communication in health care. Sometimes this role is positive and leads to better understanding and coping, to better therapeutic decisions and more compliance; sometimes, however, the role of communication is negative and leads to misunderstanding, dissatisfaction, wrong decisions and 
sometimes even malpractice suits [3,9]. The success or lack of success can often be ascribed to communication processes. It is important that doctors, nurses and other health care professionals are aware of the effects of their communication behavior and learn to use it as the powerful tool it can be. It is similarly important that communication researchers explore, unravel and test specific communication behaviors in relation to set medical and nursing goals in order to provide health care professionals with empirical evidence for the singular items of their tool-box in relation to the problems at hand. Communication is a powerful tool, but only when it is used as a tool, or rather a set of tools, as consciously planned and targeted interventions.

Aside from its well-known and widely trained generic characteristics (creating a good interpersonal relationship, exchange of information), concrete communication strategies and behaviors can be used to reach specified goals within medical and nursing care. As was shown by many authors, there is a multitude of different specific goals and sub-goals within health care $[3,5,10,11]$. Dependent on the phase of treatment and/or patient needs, medical encounters may vary in what both participants aim at: getting or giving reassurance, finding and telling the right diagnostic label, establishing a common agenda, weighing diagnostic and/or risk information, valuing preferred therapeutic options and alternative solutions, making patient preferences more explicit, reaching a medical decision (shared or not), strengthening self-efficacy in maintaining difficult therapeutic regimens, acknowledging, fighting or relieving anxiety and depression, moral support in accepting the unacceptable, comfort and strength. Even within one medical visit different targets can be distinguished. It is essential that researchers should be aware of these multiple goals in health care encounters and realize that different goals ask for varied communication strategies that are based on a variety of theoretical frameworks.

Let us give one example: How to create a good interpersonal relationship can best be predicted from psychotherapeutic theories with their heavy accent on affective communication behaviors:

friendliness, social courtesies, empathy, showing respect and understanding, 'unconditional positive regard' [12]. However, these theories might be worthless and its accompanying behaviors sometimes even contra-productive when trying to tackle the best hidden taboo in medical encounters: noncompliance. Based on self-regulatory theories [13], it can be predicted that enhancing compliance asks for active problem-solving behaviors, combined with active stress-reduction: motivating patients for taking responsibility, helping in setting realistic and tailor-made personal goals, helping in listing possible barriers, showing understanding for incidental events of non-compliance and showing partnership in creative problem-solving. A nice example of what this might mean for communication research is shown by Roter and Hall [14].

Different problems ask for specific tools, and - thus - for specific communication strategies and behaviors. This poses communication researchers for methodological as well as theoretical challenges. Methodological challenges are to be found in subdividing medical encounters in to meaningful elements, and in innovative ways of analyzing communication data (sequential analysis, pattern analysis, critical incident analysis, cue responding, etc.). Theoretical challenges are to be found in applying theories that have been developed in clinical psychology, social psychology and health psychology to the field of communication research and vice versa. As an additional advantage, this could help to explain under which conditions theoretically based behavioral intervention programs are more or less successful when implemented in everyday practice. For, as stated above: Good technical quality care, provided in an unsatisfactory environment and with unsatisfactory interactions will not produce healthier patients.

The issue is further complicated by the fact that there are often individual differences in the targets patients may have. Again an example might be illustrative. This time it is about the recent paradigm on shared decision making. There is ample evidence that patients diagnosed with cancer want to be adequately informed of their diagnosis and prognosis, but that many (but not all!) relinquish decisional control [15-17]. Patients may feel burdened by the significance and consequences of making treatment decisions and may prefer the physician to be accountable for the choices made. Therefore, advocating increased patient involvement for every patient in every situation may well endanger rather than safeguard patient autonomy [18]. 


\subsection{Towards a time perspective}

In most communication research literature, there is hardly any recognition of past or future. Continuity of care (with the same or other health care providers) is a central issue in health care, but it is hardly an issue in communication research [19]. Most dialogues are studied as if previous consultations did not leave the patient with specific uncertainties, hopes and expectancies, and as if everything has to take place during the consultation under study. From the patient's perspective, receiving bad news may reflect the process of being diseased (e.g. by cancer), whereas research on breaking bad news primarily focuses on how to provide information in the course of a single diagnostic consultation [20]. In addition, previous contacts set the agenda for the future contacts and should be taken into consideration when examining the content, process and effects of a single encounter.

Theories from research into the placebo-effect of the provider-patient encounter $[4,21,22]$ could well complement the theoretical and methodological insights gathered so far in studies into communication. Investigating the role of conditioning and expectancies in ongoing encounters could bring forward a new field of study not yet explored within the field of medical communication. The theory of classical conditioning can, for instance, be used to explain why one patient suffers from serious side-effects (e.g. from chemotherapy) and another one does not or why patients with serious complaints respond positively to a treatment and others with the same complaints do not. Apparently, previous experiences with certain treatments, hospitals or doctors influence the way patients respond to future ones. In view of the conditioning theory: a current treatment may be associated with an earlier experience which has resulted in a reduction in negative symptoms, this earlier experience is said to be positively conditioned as far as recovery and anxiety reduction is concerned [23]. This makes it extremely important to look at patients' medical history but also to look at what actually happened in former visits and at the way physicians attend to patients' experiences with health care so far. Eliciting patients' past experiences with the health care system, including these subjective experiences can help the clinician to understand patients' reactions to treatment proposals, personal preferences and unspoken resistances.

The role of expectancies, the other central placebo theory [22], has more to do with explaining why experiences in the present influence future treatment outcome [4]. Response expectations appear to be triggered by the information a person receives [24]. Research shows that physicians-by their communication behavior-are able to influence patients' expectations in a positive as well as a negative direction.

From the neuro-cognitive sciences, it is known that the brain can be blocked from acquiring new information when persons are under stress $[25,26]$. This means that in stressful situations information giving must be carefully dosed, repeated and spread over more visits. It can be experimentally tested what delay is necessary to allow for new information to be given to the patient. The role of stressreducing communication techniques in this process is another topic of research. It is worthwhile to look for opportunities to combine this line of research with neuro-imaging techniques, such as PET or MRI-scans.

\subsection{Between knowing and doing}

Chronic and life-threatening diseases go hand in hand with strong emotions and much uncertainty. Doctors and nurses may feel barriers in emotion-laden communication because it produces stress. From stress-coping theories, it can be hypothesized that experienced stress in doctors and nurses will lead to blocking behaviors as a coping strategy while facilitating communicative behaviors are needed from the patients' point of view $[27,28]$. This could explain the discrepancy between doctors' attitudes, which tend to be rather patient-centered in general, and patients' assessments of the quality of care, which focus on problems in information giving and personal care [29].

Doctors and nurses may not only feel stressed as a result of not being able to relieve the burden of the disease from their patients' shoulders, but also as a result of organizational demands. Time constraints and schedules, treatment protocols and institutional norms and values may all distract attention from patient's needs for individualized care. Time constraints, for instance, force many physicians to interrupt their patients' flow of speech at the beginning of the consultations [30]. Providers, convinced that they know patients' reason for encounter, may incorrectly focus on an issue which is not the 
patient's main concern. This may engender the risk of making incorrect diagnoses and of giving inappropriate advices on the part of the physician and dissatisfaction, non-compliance and second opinion-seeking on the part of the patient. A recent study shows that cancer patients indeed often seek a second opinion because they are dissatisfied with the way they have been treated by the first physician [31]. Although the issue of time has frequently been attended to in communication research, it has, so far, mostly been examined in a retrospective way, i.e. by examining the communication process in relation to consultation length [32]. Less attention has been given to the influence of the time pressure experienced by a health care provider at the beginning of the visit on the actual communication process.

In addition, treatment protocols and guidelines developed to improve and standardize the information exchange may also hinder a patient-centered process. Institutionalized norms and values, reflected in a supervisor's attitude towards good health care, are also likely to color the actual communication process. A supervisor may play a fairly prominent role in explaining why communication skills thoroughly acquired in training are not observed in real-life nursing care [33]. The extent in which a supervisor supports the nurse's communication style appears to have a large impact on the actual communication process. Especially affective communication suffers from such contextual constraints.

From the theory of cognitive dissonance it can be hypothesized that doctors and nurses who are highly dependent on organizational norms and values will tend to conform to this at the cost of care tailored to the patient, while doctors (and to a lesser degree nurses) who prioritize patient care above institutional demands probably show more patient-centered communication behavior.

\subsection{Beyond the dialogue}

Traditionally, research on provider-patient communication has focused on the doctor-patient dyad. Yet, in daily medical practice, physicians often find themselves faced to communicate with an elaborate and complicated patient-system. Many health care visits, especially those with a strong emotional component in case of patients with a life-threatening disease, involve more than two participants: an elderly patient accompanied by a spouse or adult child, couples visiting a doctor, parents consulting a doctor for their child or, in case of non-native speakers, interpreters supporting a patient.

Due to the myopic dyadic perspective there has been little empirical exploration on the role and influence of a third (or fourth) person's presence on the process, content and outcome of the medical visit. The scarce research on multi-party medical interactions within the setting of pediatrics [34-36], geriatrics [37], dietary counseling [38] and the general practitioner's surgery $[39,40]$ showed that the mere presence of a third person changes the dynamics of the medical interaction, no matter how small the third person's conversational contribution to the actual visit. After all, in attending a health care provider, patients have their agenda (needs and expectations) but so have the persons accompanying the patient. In order to communicate effectively, the health care provider should not only consider the patients' viewpoints but those of their relatives as well.

In emotionally laden consultations, caregivers or relatives are likely to make themselves especially felt. Therefore, an appropriate avenue for future communication research would be to explore the implications regarding participant roles and responsibilities beyond the scope of the medical dialogue. In view of the social support theory, the relative's presence should not be ignored but rather be encouraged for its positive impact on the patient's quality of life [41]. Fruitful theoretical frameworks may be derived from social psychology, in particular from social support theories [42] and theories on family coping [43]. Many of these theories lead to explicit assumptions about communication behaviors that are beneficial or detrimental for the patients' well-being.

Not only patients are part of a larger system, even within the consultation room. Future research should also pay attention to the multifaceted character of the health care system itself. Patients are often confronted with a broad range of health care providers, such as specialists, nurses, and radiologists. These providers are likely to differ in attitudes, experience and skills. Inadequate communication, due to discordance in information or insufficient fine-tuning of information conveyed by the various providers, can lead to confusion for patients about the diagnosis, the prognosis and the future management plans. Studies indeed showed that patients often feel overwhelmed by contradictory advice or an overloaded information supply emanating from multidisciplinary sources 
Patient Education and Counseling: 50, 2003, nr. 1, p. 27-32

[44]. Not only may this cause unnecessary stress for patients, but also for health care providers themselves. After all, effective communication has shown to be important for the efficiency, morale and work satisfaction of the individual providers [45]. So far, however, little data are available on how the process of information exchange between provider and patient is influenced by factors such as task-distribution and delegation and fine-tuning and checking of the information conveyed. Research into the expectations of breast cancer team members of their own and each other's roles in providing information to women with breast cancer showed that even the members of these multidisciplinary teams are not completely acquainted with the informational roles and responsibilities of their colleagues [45]. These findings may cause concern, as one of the tenets of this type of multidisciplinary care is the provision of comprehensive and consistent information. Further research is required to capture health care providers' views on what they consider as their individual task and responsibility in the process of exchanging and tailoring the information supply.

Decontextualized dyadic analyses are bound to fail in fully exposing the dynamics of multi-party medical communication. By acknowledging the multi-party character of medical communication, future research will have to take into account the context of the medical communication both on the patient's and on the provider's side. Fruitful areas of research might also be communication studies on small group interactions and organizational theory on interdisciplinary collaboration. New advances are to be made in order to capture the impact of these contextual factors on the course and outcome of the medical 'dialogue'.

\section{CONCLUSION}

In this paper, we proposed to expand the focus of communication research and to incorporate the context in which a single health care visit takes place. This broader context was defined in four different ways, i.e. by referring to the multiple goals of and within a medical encounter, by incorporating the concept of time which necessitates to look beyond a single encounter, by considering the organizational context of treatment policy and constraints, and by acknowledging the fact that a large number of encounters include more than two parties. In proposing these lines of research our point of departure was the actual communication process within health care, not the context itself, which could of course, be defined in a number of alternative ways.

In the way defined in the present paper, the broader context perspective is considered to be necessary to find out, for instance, why health care professionals do not always act in conformity with the general approved standards of high quality communication-although they are known to have mastered the skills in training, how the factor time span can be used more effectively in the medical encounter and what the reasons are why patients not always disclose their concerns assessed prior to the health care visit. Eventually, a broader context view will bridge the existing gap between theory and practice.

\section{REFERENCES}

[1] White K. The task of medicine. Menlo Park, Califormia: The Henry J. Kaiser Family Foundation; 1988.

[2] Bensing JM. Bridging the gap: the separate worlds of evidence-based medicine and patientcentered medicine. Patient Educ Couns 2000;39:17-25.

[3] Roter DL, Hall JA. Doctors talking with patients/patients talking with doctors. Improving communication in medical visits. Westport, Connecticut: Auburn House; 1992.

[4] Crow R, Gage H, Hampson S, Hart J, Kimber A, Thomas H. The role of expectancies in the placebo-effect and their use in the delivery of health care: a systematic review. Health Technol Assess 1999;3:1-96.

[5] Lipkin M, Putnam SM, Lazare A. The medical interview: clinical care, education and research. New York: Springer; 1995.

[6] Bensing JM. Doctor-patient communication and the quality of care: an observational study into affective and instrumental behaviour. Utrecht: NIVEL; 1991.

[7] Koehler WF, Fottler MD, Swan JE. Physician-patient satisfaction: equity in the health services encounter. Med Care Rev 1992;49:455- 84. 
Bensing, J., Dulmen, S. van, Tates, $\mathrm{K}$.

Communication in context: new directions in communication research.

Patient Education and Counseling: 50, 2003, nr. 1, p. 27-32

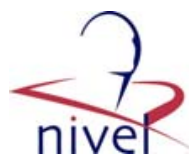

[8] van Dulmen AM, Bensing JM. The effect of context in healthcare a programming study, vol. 3. ISBN: 9014655-5. The Hague: RGO; 2001.

[9] Levinson W, Roter DL, Mullooly JP, Dull V, Frankel RM. The relationship with malpractice claims among primary care physicians and surgeons. JAMA 1997;277:553-9.

[10] Ong LM, de Haes JC, Hoos AM, Lammes FB. Doctor-patient communication: a review of the literature. Soc Sci Med 1995;40:903- 18.

[11] Lazare A, Putnam SM, Lipkin M. Three functions of the medical interview. In: Lipkin M, Putnam SM, Lazare A, editors. The medical interview. Clinical care, education and research. New York: Springer; 1995.

[12] Rogers CR. The characteristics of a helping relationship. In: Rogers CR, editor. On becoming a person: a therapist's view of psychotherapy. Boston: Houghton Mifflin; 1961.

[13] Leventhal H, Safer MA, Panagis DM. The impact of communications on the self-regulation of health beliefs, decisions, and behavior. Health Educ Q 1983;10:3-29.

[14] Roter DL, Hall JA. Strategies for enhancing patient adherence to medical recommendations. JAMA 1994;271:80.

[15] Coulter A. Partnerships with patients: the pros and cons of shared clinical decision-making. J Health Serv Res Policy 1997;2:112-21.

[16] Stiggelbout AM, Kiebert GM. A role for the sick role: patient preferences regarding information and participation in clinical decision-making. CMAJ 1997;157:383-9.

[17] Fallowfield LJ, Jenkins VA, Beveridge HA. Truth may hurt but deceit hurts more: communication in palliative care. Palliat Med 2002;16:297-303.

[18] Gattellari M, Voigt KJ, Butow PN, Tattersall MH. When the treatment goal is not cure: are cancer patients equipped to make informed decisions? J Clin Oncol 2002;20:503-13.

[19] van Dulmen AM, Verhaak PFM, Bilo HJG. Shifts in doctor-patient communication during a series of outpatient consultations in non-insulin-dependent diabetes mellitus. Patient Educ Couns 1997;30:227-37.

[20] Salander P. Bad news from the patient's perspective: an analysis of the written narratives of newly diagnosed cancer patients. Soc Sci Med 2002;55:721-32.

[21] Di Blasi Z, Harkness E, Ernst E, Georgiou A, Kleijnen J. Influence of context effects on health outcomes: a systematic review. Lancet 2001;357:757-62.

[22] van Dulmen AM, Bensing JM. Health promoting effects of the physician-patient encounter. Psych Health Med 2002;7:289-300.

[23] Kvale G, Hugdahl K, Asbjørnsen, Rosengren B, Lote K, Nordby H. Anticipatory nausea and vomiting in cancer patients. J Cons Clin Psychol 1991;59:894-8.

[24] Thomas KB. General practice consultations: is there any point in being positive? Br Med J 1987;294:1200-2.

[25] Newcomer JW, Selke G, Melson AK, Hershey T, Craft S, Richards K, et al. Decreased memory performance in healthy humans induced by stress-level cortisol treatment. Arch Gen Psychiatr 1999;56:527-33.

[26] Bremner JD. Does stress damage the brain? Biol Psychiatr 1999;45:797-805.

[27] de Valck C, Bruynooghe R, Hulsman RL, Kerssens JJ, Bensing JM. Cue responding in a simulated bad news situation. J Health Psychol 2001;6:585-96.

[28] Kruijver IPM, Kerkstra A, Bensing JM, van de Wiel HBM. Nurse-patient communication in cancer care. Cancer Nursing 2000;23:20-31.

[29] deValck C. Responding to patient cues in a video simulated bad news consultation. Thesis, Leuven; 2002.

[30] Marvel MK, Epstein RM, Flowers K, Beckman HB. Soliciting the patient's agenda: Have we improved? JAMA 1999;281:283-7.

[31] Mellink WAM, van Dulmen AM, Wiggers Th, Spreeuwenberg PMM, Eggermont AMM, Bensing JM. Cancer patients seeking a second opinion: results of a study on motives, needs and expectations [in revision].

[32] DeVeugele M, Derese A, van den Brink-Muinen A, Bensing J, De Maeseneer J. Consultation length in general practice: cross-sectional study in six European countries. Br Med J 2002;325:472.

[33] Kruijver IPM. Communication between nurses and admitted cancer patients: the evaluation of a communication training program. Thesis, Utrecht: NIVEL; 2001.

[34] Aronsson K. Facework and control in multi-party talk: a pediatric case study. In: Markovà I, Foppa K, editors. Asymmetries in dialogue. New York: Harvester; 1991. p. 49-74.

[35] van Dulmen AM. Children's contribution to pediatric outpatient encounters. Pediatrics 1998;102:563-8. 
Patient Education and Counseling: 50, 2003, nr. 1, p. 27-32

[36] Wissow LS, Roter D, Bauman LJ, Crain E, Kercsmar C, Weiss K, et al. Patient-provider communication during the emergency department care of children with asthma. Med Care 1998;36:1439-50.

[37] Greene MG, Majerovitz SD, Adelman RD, Rizzo C. The effects of the presence of a third person on the physician-older patient medical interview. J Am Geriatr Soc 1994;42:413-9.

[38] Pyörälä E. Interaction in dietary counselling of diabetic children and adolescents. Thesis, Helsinki: Helsinki University Press; 2000.

[39] Tates H, Meeuwesen L, Elbers E, Bensing J. I have come for his throat': roles and identities in doctor-parent-child communication. Child Care Health Dev 2002;28:109-16.

[40] Tates K, Elbers E, Meeuwesen L, Bensing J. Doctor-parent-child relationships: a 'pas de trois'. Patient Educ Couns 2002;48:5-14.

[41] Kamarck TW, Peterman AH, Raynor DA. The effects of the social environment on stress-related cardiovascular activation: current findings, prospects, and implications. Ann Behav Med 1998;20:247-56.

[42] Cutrona CE. Social support in couples marriage as a resource in times of stress. Thousand Oaks, CA: Sage; 1996.

[43] Coyne JC, Smith DA. Couples coping with a myocardial infarction: contextual perspective on patient self-efficacy. J Fam Psych 1994;8:43-54.

[44] Weert van JCM, van Dulmen AM, Bär P, Venus E. Multidisciplinary preoperative patient education in cardiac surgery. Patient Educ Couns 2002;49:105-14.

[45] Jenkins VA, Fallowfield LJ, Poole K. Are members of multidisciplinary teams in breast cancer aware of each other's informational roles? Qual Healthcare 2000;10:70-5. 